\title{
Identifications of 9-Oxononanoic Acid and Hexanal in Liver of Rat Orally Administered with Secondary Autoxidation Products of Linoleic Acid
}

\author{
Kazuki Kanazawa and Masato NataKe \\ Department of Agricultural Chemistry, Kobe University, \\ Nada-ku, Kobe 657, Japan
}

Received June 26, 1985

\begin{abstract}
Secondary autoxidation products (SP) of $\left[{ }^{14} \mathrm{C}\right.$-U]linoleic acid were administered orally to rats and the incorporation of SP into the body was investigated. The radioactivity of SP was incorporated into the liver after $12 \mathrm{hr}$ to the extent of $1 \sim 2.5 \%$. An attempt was then made to detect the major low molecular-weight components of SP, 9-oxononanoic acid (9-ONA) and hexanal, in the hepatic mitochondrial and microsomal lipids. The fraction containing SP could be separated from the neutral and phospholipids of the organelles and their peroxides by silica gel column chromatography. The specific activity of the thiobarbituric acid-reactive substances of the fraction approached the value of SP per se, and with gas chromatographic-mass spectrometric analysis, 9ONA and hexanal were identified in the fraction. These detected compounds could not be artifacts and, therefore, were originated from the SP orally administered.
\end{abstract}

Endogenous lipid peroxidation is associated closely with serious diseases ${ }^{1 \sim 4)}$ and senescence $^{5 \sim 7)}$ in animals. The biological roles of peroxidation products have been clarified over the past several years. ${ }^{8 \sim 10}$ )

Polyunsaturated fatty acids react easily with atmospheric oxygen to form their hydroperoxides (HPO). These HPO are broken down in the presence of oxygen ${ }^{11)}$ and give a mixture of further oxidized products. ${ }^{12)}$ The mixture is generally termed secondary autoxidation products (SP). Although the amounts of these autoxidation products may not always be high with recently improved food technology, it is fact that autoxidation products occur in our daily foods. An interesting nutritional question is whether autoxidation products given orally are absorbed into body or not. ${ }^{13)}$ We previously reported on the uptakes of $\left[{ }^{14} \mathrm{C}-\mathrm{U}\right]$ linoleic acid (LA), its hydroperoxide (LAHPO) and SP into the rat body. ${ }^{14)}$ Radioactive substances of LA, LAHPO and SP were incorporated into the bodies to the extent of $95 \%, 85 \%$ and $55 \%$ of their respective administered amounts.
The next question is whether the autoxidation products are incorporated into body in unchanged form or not. The incorporation of LAHPO has been investigated by many workers, Holman and Greenberg ${ }^{15)}$ demonstrating that the intraperitoneal $\mathrm{LD}_{50}$ of ethyl linoleate hydroperoxide for mice is $12 \mathrm{mg}$ and that an oral dose does not kill. Bergan and Draper ${ }^{16)}$ reported that oral $\left[1-{ }^{14} \mathrm{C}\right]$ methyl linoleate hydroperoxide is not absorbed per se into the animal body. Nakatsugawa and Kaneda ${ }^{17)}$ showed that only $0.23 \%$ of methyl linoleate hydroperoxide in the orally administered total can be detected in rabbit lymph by high performance liquid chromatography. Thus, it is believed that orally fed LAHPO is readily decomposed to $\mathrm{SP}^{18 \sim 20)}$ or reduced to nontoxic substances such as hydroxy $\mathrm{FA}^{15,16,21)}$ in animals.

However, little has been reported on the absorption of orally administered SP. ${ }^{22)} \mathrm{SP}$ is a mixture of various kinds of autoxidation products: polymers, acids, aldehydes and so on. In our previous paper, ${ }^{14)}$ the radioactive SP was separated into three fractions of 
polymers, endoperoxides and epoxyhydroperoxides, and low molecular-weight components. When these fractions were orally administered to rats, their radioactivities were incorporated into the body. However, the polymers, endoperoxides and epoxyhydroperoxides might decompose under a such acidic conditions that exist in the stomach. Gardner and Selke reported that epoxyhydroperoxides were decomposed under acidic conditions and subsequently 9-oxononanoic acid (9-ONA), hexanal and so on were produced. ${ }^{23)}$ 9-ONA and hexanal were also major components in the low molecular-weight fraction of SP. ${ }^{12)}$ In the present study, the radioactive SP was orally administered to rats and an attempt was made to detect 9ONA and hexanal in the liver.

\section{MATERIALS AND METHODS}

$S P .\left[{ }^{14} \mathrm{C}-\mathrm{U}\right] \mathrm{LA}$ (New England Nuclear, Boston) was diluted with cold LA (Tokyo Kasei Kogyo Co., Ltd.) to specific activity of $172 \mathrm{kBq} / \mathrm{mmol}$. The radioactive LA was autoxidized in air at $37^{\circ} \mathrm{C}$ for 7 days and submitted to silica gel column and thin layer chromatographies. The SP fraction was collected and analyzed with gas chromatography-mass spectrometry (GC-MS) and Sephadex LH-20 gel filtration chromatography. ${ }^{12)}$ The SP fraction consisted of a $36 \%$ mixture of polymers, $26 \%$ of epoxyhydroperoxides or endoperoxides, $4.8 \%$ of 9-ONA, $3.7 \%$ of hexanal, $2.5 \%$ of nonanedioic acid, $2.4 \%$ of shortchain carboxylic acids, $0.75 \%$ of 8 -oxooctanoic acid, $0.34 \%$ of 12 -oxododecadienoic acid and the remainder. The specific activity of SP was $46.4 \mathrm{kBq} / 100 \mathrm{mg}$.

Animals and diet. Male Wistar albino rats, 5 weeks old and each weighing about $110 \mathrm{~g}$ (Clea Japan, Inc.), were housed at approximately $23^{\circ} \mathrm{C}$ with a light and dark cycle of $12 \mathrm{hr}$ each, and fed with a fresh diet for 1 week. The diet was prepared daily and its peroxide value was maintained at less than $0.5 \mathrm{meq} / \mathrm{kg}$. It consisted of $30 \%$ of sucrose, $24 \%$ of corn starch, $25 \%$ of casein, $15 \%$ of soybean oil, $4 \%$ of McCollum's salt mixture, $1 \%$ of cellulose powder and $1 \%$ of vitamin mixture. The vitamin mixture was purchased from Shionogi and Co., Ltd. and the solution of $1 \mathrm{ml}$ contained $2500 \mathrm{IU}$ of retinyl palmitate, $2.5 \mathrm{mg}$ of thiamine hydrochloride, $3.5 \mathrm{mg}$ of riboflavin phosphate, $2.5 \mathrm{mg}$ of pyridine hydrochloride, $25 \mathrm{mg}$ of nicotinamide, $10 \mathrm{mg}$ of panthenol, $75 \mathrm{mg}$ of ascorbic acid, $250 \mathrm{IU}$ of calciferol and $100 \mathrm{mg}$ of lysine hydrochloride. Food was withheld for $4 \mathrm{hr}$ and then a dose of the radioactive SP was given intragastrically to each rat using a tuberculin sy- ringe. The administered amounts were determined by measuring the radioactivity remaining in the syringes. The radioactivity was measured with a scintillation counter (Rack Beta 1215, LKB Wallac) using a PCS scintillation cocktail (Amersham Co.).

Isolation of hepatic mitochondria and microsomes. The rat liver was homogenized with 10 volumes of $0.25 \mathrm{M}$ sucrose contatining $1 \mathrm{~mm}$ ethylenediaminetetraacetate and $1 \mathrm{~mm}$ tris buffer (pH 7.4) in a Teflon homogenizer. After initial centrifugation for $10 \mathrm{~min}$ at $700 \times g$ the supernatant fraction was subjected to further centrifugation for $10 \mathrm{~min}$ at $12,000 \times g$. The supernatant was submitted to isolate the microsomes, and the pellet was resuspended to the original volume in the same sucrose. After further centrifugation for $15 \mathrm{~min}$ at $9000 \times g$, the pellet was resuspended in $150 \mathrm{mM}$ of $\mathrm{KCl}$ and was used for experiments as the mitochondrial fraction. The supernatant at $12,000 \times g$ was recentrifuged at $24,000 \times g$. The supernatant fraction was subjected to further centrifugation at $54,000 \times g$ and the pellet was resuspended in $150 \mathrm{~mm}$ of $\mathrm{KCl}$, this being referred to as the microsomal fraction. The fractions of mitochondria and microsomes were each added to $2.0 \mathrm{mg}$ of butylated hydroxytoluene (BHT). After the supernatant at $54,000 \times g$ was recentrifuged at $105,000 \times g$, the supernatant was used as the cytosol fraction. The nitrogen contents in these fractions were measured by the Kjeldahl method.

Silica gel column chromatography of mitochondrial and microsomal lipids. The suspensions of mitochondria and microsomes were homogenized three times with 2 volumes of a chloroform-methanol $(1: 2)$ solvent in a Teflon homogenizer. The chloroform layer was evaporated, dissolved again in chloroform and applied to a $1 \times 17 \mathrm{~cm}$ column of silica gel (Wakogel C-100). The chromatography followed the method of Rouser et al..$^{24)}$; that is, $200 \mathrm{ml}$ of chloroform, $800 \mathrm{ml}$ of acetone and $200 \mathrm{ml}$ of methanol were eluted in succession. Standard samples of SP, LAHPO, HPO of phosphatidylethanolamine (PE), and HPO of trilinolein (TL) were also chromatographed. LAHPO was prepared by the autoxidation of LA and then purified. ${ }^{25)}$ The HPO of PE (Sigma Chem. Co., Ltd.) and TL (Nakarai Chem. Co., Ltd.) were obtained by photosensitized oxidation. ${ }^{26)}$ The HPO were detected by the peroxide value test ${ }^{27)}$ and the concentration is expressed as meq of iodine.

Thiobarbituric acid (TBA) test. The TBA test of Asakawa and Matsushita ${ }^{28)}$ was modified. A sample $(2 \mathrm{ml})$ was added to the TBA-reaction mixture consisting of $2 \mathrm{ml}$ of TBA reagent $(0.5 \%$ of TBA in $50 \%$ of acetic acid), $2 \mathrm{ml}$ of acetic acid and $0.1 \mathrm{ml}$ of BHT $(25 \mathrm{~mm}$ in ethanol). The mixture was saturated with nitrogen and heated for a short period $(15 \mathrm{~min})$ to avoid any concomitant autoxidation of lipids contaminants. The optical density is presented as neq of malonaldehyde (MA). 
$G C-M S$ analysis. The samples were methylesterified by diazomethane gas and applied to a Hitachi GC-MS (Model 6MG) with a $1 \mathrm{~m}$ column of Silicon OV-1 (2\%) on gas chrom Q (60 80 mesh) after BHT had been added as an internal standard. The analytical conditions were an elevation of temperature from $60^{\circ} \mathrm{C}$ to $250^{\circ} \mathrm{C}$ at $10^{\circ} \mathrm{C} / \mathrm{min}$; flow pressure of helium gas of $1 \mathrm{~kg}$; ionic voltage of $20 \mathrm{eV}$; sample temperature of $100^{\circ} \mathrm{C}$ and a chamber temperature of $200^{\circ} \mathrm{C}$. These conditions were almost the same as those for the analysis of the low molecular weight components of SP. ${ }^{12)}$

\section{RESULTS}

Incorporation of the radioactivity of orally given $S P$ into hepatic mitochondria and microsomes When the radioactive SP was orally administered to rats, the radioactive substances accumulated mainly in the liver within $12 \sim 24 \mathrm{hr}$ after administration. ${ }^{14)}$ Various amounts of SP were then administered to rats and the accumulated amounts in the liver were measured after $12 \mathrm{hr}$ (Table I). The accumulation ratio in the liver decreased noticeably from $2.5 \%$ to $1 \%$ as the amounts administered were increased from $100 \mathrm{mg}$ to $570 \mathrm{mg}$. The radioactive substances of SP accumulated in the liver were almost constant at $3 \sim 5 \mathrm{mg}$.

The hepatic mitochondria and microsomes were isolated from the other cellular components. Table II shows the radioactivity in these organelles for rats given $350 \mathrm{mg}$ each of SP. The radioactivity in both the mitochondria and microsomes increased with time after each administration, and the activity in the other components reached a maximum at $12 \mathrm{hr}$. On the other hand, the accumulation ratios of both mitochondria and microsomes were almost constant $(10 \%$ of the radioactivity of the whole liver) and the same as in the case of LAand LAHPO-administration.

Separation of SP from the hepatic mitochondrial and microsomal lipids

An attempt was made to separate SP from the hepatic lipids and their peroxides. When the authentic SP was applied to silica gel column chromatography, SP was present in the acetone eluate (Table III). LAHPO, HPO of TL and HPO of PE were prepared and were also applied to the column. LAHPO and HPO

Table I. InCORPORation of Radioactive SubSTances INTO THE LIVER $12 \mathrm{hr}$ AFTER VARIOUS AMOUNTS of SP Were Orally Given

\begin{tabular}{ccc}
\hline \multirow{2}{*}{$\begin{array}{c}\text { Administered } \\
(\mathrm{mg})^{a}\end{array}$} & \multicolumn{2}{c}{ Incorporated into liver } \\
\cline { 2 - 3 } & $(\mathrm{mg})^{a}$ & $(\%)$ \\
\hline 115 & $3.00^{b}$ & 2.6 \\
230 & 4.03 & 1.8 \\
300 & 4.29 & 1.4 \\
410 & 4.63 & 1.1 \\
570 & 4.90 & 0.9 \\
\hline$a \quad$ These amounts & were calculated from their \\
& radioactivity. & \\
$b \quad$ From a previous paper. & &
\end{tabular}

Table II. InCORporation of Radioactive Substances into HePatic Mitochondria and Microsomes When SP Was Orally Given

\begin{tabular}{|c|c|c|c|c|}
\hline \multirow{2}{*}{$\begin{array}{c}\text { Hr after } \\
\text { administration } \\
\text { of chemicals }\end{array}$} & \multicolumn{4}{|c|}{$\begin{array}{l}\text { Incorporated radioactivity } \\
\quad(\mathrm{Bq}: \text { mean } \pm \text { S.E., } n=4)\end{array}$} \\
\hline & Whole liver & Mitochondria & Microsomes & Supernatant \\
\hline $3 \mathrm{hr}-\mathrm{SPP}$ & $424 \pm 54$ & $54 \pm 5$ & $36 \pm 4$ & $326 \pm 24$ \\
\hline $7 \mathrm{hr}-\mathrm{SP}$ & $669 \pm 63$ & $52 \pm 7$ & $33 \pm 4$ & $247 \pm 5$ \\
\hline $12 \mathrm{hr}-\mathrm{SP}$ & $1982 \pm 228$ & $188 \pm 16$ & $142 \pm 24$ & $540 \pm 15$ \\
\hline $24 \mathrm{hr}-\mathrm{SP}$ & $1636 \pm 156$ & $210 \pm 16$ & $146 \pm 15$ & $297 \pm 18$ \\
\hline $7 \mathrm{hr}-\mathrm{LA}^{a}$ & $1769 \pm 229$ & $156 \pm 12$ & $126 \pm 1$ & $814 \pm 89$ \\
\hline $7 \mathrm{hr}-\mathrm{LAHPO}^{a}$ & $1851 \pm 262$ & $157 \pm 4$ & $124 \pm 17$ & $889 \pm 74$ \\
\hline Recovery of nitrogen & $100 \%$ & $18.2 \pm 0.3 \%$ & $7.98 \pm 0.24 \%$ & $24.1 \pm 0.3 \%$ \\
\hline
\end{tabular}

${ }^{a}$ Radioactive LA and LAHPO $\left(46.4 \mathrm{kBq}\right.$ each) were orally administered as described in a previous paper. ${ }^{14)}$ 
TABle III. SeParation of SP From Lipid Peroxides

\begin{tabular}{lcccc}
\hline Sample & SP & LAHPO & HPO of TL & HPO of PE \\
\cline { 3 - 5 } $\begin{array}{c}\text { Analysis } \\
\text { method }\end{array}$ & $\begin{array}{c}\text { Radioassay } \\
(\mathrm{kBq})\end{array}$ & & $\begin{array}{c}\text { Peroxide value test } \\
(\text { meq })\end{array}$ & \\
\hline Applied amount & 11.7 & 870 & 399 & 190 \\
Eluted with: & & & & 12 \\
$\quad$ Chloroform & & & 308 & 19 \\
Acetone & 0.1 & 39 & 59 & 140 \\
Methanol & 11.4 & 16 & 16 & \\
\hline
\end{tabular}

a BHT was eluted into the chloroform fraction.

Table IV. SPecific Activity of TBARS

Contained in the Acetone Fractions of Hepatic Organelle Lipids

\begin{tabular}{ll}
\hline $\begin{array}{c}\text { Acetone } \\
\text { fraction }\end{array}$ & Mean \pm S.E. Bq/neq of MA $(n=4)$ \\
\hline Mitochondrial & $45.4 \pm 6.9$ \\
Microsomal & $47.5 \pm 6.1$ \\
Authentic SP & $47.9 \pm 0.9$ \\
\hline
\end{tabular}

a The mitochondrial and microsomal acetone fractions were obtained from the liver of rat $12 \mathrm{hr}$ after administering SP.

of TL were mainly present in the chloroform eluate and HPO of PE was eluted with methanol. It is well known that the neutral, glyco- and phospholipids can be separately eluted with chloroform, acetone and methanol from this column. ${ }^{24)}$ Thus, SP could be separated from both the neutral and phospholipids, and their HPO.

The hepatic mitochondrial and microsomal lipids of rats receiving orally the radioactive SP were then extracted with the chloroformmethanol solvent containing BHT, and were subjected to silica gel column chromatography. The specific activity of TBA-reactive substances (TBARS) contained in the acetone fraction was determined (Table IV). The specific activity of the mitochondrial acetone fraction was $45.4 \mathrm{~Bq} /$ neq and close to the value of SP per se (47.9 Bq/neq). The specific activity of microsomal TBARS was $47.5 \mathrm{~Bq} /$ neq and the same as SP alone.

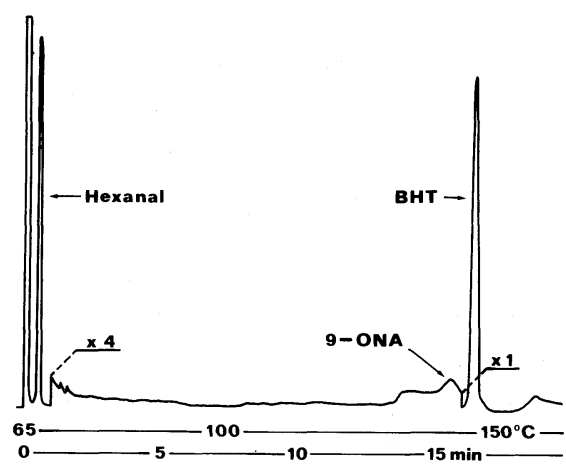

FIG. 1. Gas Chromatogram of the Acetone Fraction of Microsomal Lipids in Rats $12 \mathrm{hr}$ after Being Given SP.

\section{Identification of 9-ONA and hexanal in the acetone fractions}

An attempt was made to detect 9-ONA and hexanal in the acetone fraction of the mitochondrial and microsomal lipids by GC-MS. The acetone fractions of four rats were collected, and methylesterification was carried out with diazomethane gas to avoid interference by glycolipids. In samples obtained from the mitochondria of animals given SP after $12 \mathrm{hr}$, two peaks were observed on GC at each position agreeing with methylester of 9-ONA ${ }^{29)}$ and hexanal (Fig. 1). When these peaks were analyzed by MS, their fragmentations completely agreed with those of the methylester of 9-ONA and hexanal. ${ }^{12)}$ In samples obtained from the microsomes of animals given SP $3 \mathrm{hr}$ earlier, and from the microsomes and mitochondria of animals given SP $7 \mathrm{hr}$ earlier, a small peak was observed at the position of hexanal. This peak gave several mass fragment 
Table V. Changes in Radioactivity of the Mitochondrial and Microsomal Acetone Fractions Following SP Administration

\begin{tabular}{|c|c|c|c|c|}
\hline \multirow{3}{*}{$\begin{array}{l}\text { Hr after } \\
\text { adminis- } \\
\text { tration }\end{array}$} & \multicolumn{4}{|c|}{$\mathrm{Bq}(\%)^{a}$} \\
\hline & \multicolumn{2}{|c|}{ Mitochondria } & \multicolumn{2}{|c|}{ Microsomes } \\
\hline & $\begin{array}{l}\text { Total } \\
\text { lipids }\end{array}$ & $\begin{array}{l}\text { Acetone } \\
\text { fraction }\end{array}$ & $\begin{array}{l}\text { Total } \\
\text { lipids }\end{array}$ & $\begin{array}{l}\text { Acetone } \\
\text { fraction }\end{array}$ \\
\hline 3 & 44 & $8(18)$ & 28 & $6(21)$ \\
\hline 7 & 25 & $5(20)$ & 25 & $5(20)$ \\
\hline 12 & 142 & $14(10)$ & 118 & $8(7)$ \\
\hline 24 & 119 & $10(8)$ & 119 & $5(4)$ \\
\hline
\end{tabular}

a The organelles of Table II were assayed and the radioactivity is expressed as the mean of four samples. The percentages of radioactivity in the acetone fractions to that in the total lipids are shown in parenthesis.

ions of $m / z: 43,58$ and 71 . These ions were major fragment ions of hexanal. In the $12 \mathrm{hr}$ microsomal sample, one peak was also identified as hexanal. However, no components of SP were detected from the $24 \mathrm{hr}$-organelles.

\section{Changes in radioactivity of the acetone fraction}

Changes in the radioactivity of the acetone fraction were measured as a function of time after feeding (Table V). While the radioactivity in the total lipids of both mitochondria and microsomes increased markedly by $12 \mathrm{hr}$, the activity in the acetone fraction did not. The ratios of radioactivity decreased from $20 \%$ to $8 \%$ in the acetone fraction of mitochondria, and from $20 \%$ to $4 \%$ in the microsomes.

\section{DISCUSSION}

SP was administered orally to rats and attempt was made to detect SP in the liver. The radioactivity of SP was accumulated in the hepatic mitochondria and microsomes $12 \mathrm{hr}$ after the administration (Tables I and II). The major low molecular-weight components of SP were 9-ONA and hexanal, comprising $4.8 \%$ and $3.7 \%$, respectively, of the total weight. ${ }^{12)}$ An attempt was then made to identify 9-ONA and hexanal in the hepatic organelles.
Lipids of the organelles were extracted with a chloroform-methanol solvent and subjected to silica gel column chromatography, and the acetone fraction being collected. Data in Table III indicate that authentic SP was eluted with acetone and the HPO of the neutral and phospholipids were present in the other eluates. Therefore, SP absorbed into the liver may be contained in the acetone fraction. Furthermore, the HPO was considered not to have been produced and decomposed by these manipulations because BHT was added to the lipid extracts.

The TBA test is suitable for the detection of SP, but not for the determination of peroxides. $^{30)}$ The specific activity of TBARS in the acetone fractions agreed well with that of SP alone (Table IV). When the acetone fractions were analyzed with GC-MS, trace amounts of hexanal and 9-ONA were identified. Thus, the radioactive substances in the acetone fractions seemed to be SP per se. The compounds detected were not artifacts of these experiments as described in Table III and, therefore, were originated from the orally administered SP. Draper and coworkers have also indicated the incorporation of MA into cells. ${ }^{31 \sim 33)}$ Thus, the low molecular-weight aldehydes were considered to have been incorporated into the rat liver.

Although the incorporated radioactivity in mitochondrial and microsomal lipids increased with time, the radioactivity in the acetone fractions decreased (Table V). Both 9-ONA and hexanal could not be detected in the organelles of rats given SP after $24 \mathrm{hr}$. 9-ONA and hexanal seemed to have been metabolized in the hepatic organelles. It is concluded that the low molecular-weight components of SP given orally were incorporated and metabolized in the hepatic mitochondria and microsomes.

$\mathrm{LAHPO}^{34,35)}$ and epoxyhydroperoxides ${ }^{23)}$ easily decomposed and produced 9-ONA and hexanal under an acidic condition. When these compounds were also orally given to rats, 9ONA and hexanal may subsequently have been incorporate into the body. Consequently, 
9-ONA would damage the rat liver as described previously. ${ }^{29)}$

Acknowledgment. The authors are grateful to Professor Makoto Kito of Kyoto University for his helpful advice.

\section{REFERENCES}

1) Y. Hata, "Lipid Peroxides and Allied Diseases," ed. by K. Yagi and Y. Goto, Igaku-Shoin, Tokyo, 1981, p. 155.

2) A. Sevanian, R. A. Stein and J. F. Mead, Lipids, 16, 781 (1981).

3) O. Hayaishi and T. Shimizu, "Lipid Peroxides in Biology and Medicine," ed. by K. Yagi, Academic Press, New York, 1982, p. 41.

4) B. Halliwell and J. M. C. Gutteridge, Biochem. J., 219, 1 (1984).

5) K. S. Chio and A. L. Tappel, Biochemistry, 8, 2821 (1969).

6) D. Harman, "Free Radicals in Biology," Vol. V, ed. by W. A. Pryor, Academic Press, New York, 1982, p. 255 .

7) H. Shimasaki, N. Ueta, H. Mowri and K. Inoue, Biochim. Biophys. Acta, 792, 123 (1984).

8) L. A. Morehouse, C. E. Thomas and S. D. Aust, Arch. Biochem. Biophys., 232, 366 (1984).

9) P. Moldéus, P. J. O'Brien, H. Thor, M. Berggren and S. Orrenius, FEBS Lett., 162, 411 (1983).

10) J. Terao, I. Asano and S. Matsushita, Arch. Biochem. Biophys., 235, 326 (1984).

11) K. Kanazawa, T. Mori and S. Matsushita, J. Nutr. Sci. Vitaminol., 19, 263 (1973).

12) K. Kanazawa, G. Danno and M. Natake, Agric. Biol. Chem., 47, 2035 (1983).

13) W. A. Pryor, "Xenobiotic Metabolism; Nutritional Effects," ACS Symposium Series 277, ed. by J. W. Finley and D. E. Schwass, Am. Chem. Soc., Washington, 1985, p. 77.
14) K. Kanazawa, E. Kanazawa and M. Natake, Lipids, 20, 412 (1985).

15) R. T. Holman and S. I. Greenberg, J. Am. Oil Chem. Soc., 35, 707 (1958).

16) J. G. Bergan and H. H. Draper, Lipids, 5, 976 (1970).

17) K. Nakatsugawa and T. Kaneda, Yukagaku, 30, 74 (1980).

18) P. Dubouloz, J. Fondarai and C. Lagarde, Biochim. Biophys. Acta, 3, 371 (1949).

19) J. Glavind and N. Tryding, Acta Physiol. Scand., 49, 97 (1960).

20) P. J. O'Brien and A. C. Frazer, Proc. Nutr. Soc., 25, 9 (1966).

21) R. Cortesi and O. S. Privett, Lipids, 7, 715 (1972).

22) L. R. Tovar and T. Kaneda, Yukagaku, 26, 169 (1977).

23) H. W. Gardner and E. Selke, Lipids, 19, 375 (1984).

24) G. Rouser, G. Kritchevsky and A. Yamamoto, "Lipid Chromatographic Analysis," ed. by G. V. Marinetti, Vol. I, Dekker, New York, 1967, p. 99.

25) K. Kanazawa, G. Danno and M. Natake, J. Nutr. Sci. Vitaminol., 21, 373 (1975).

26) J. Terao, Y. Hirota, M. Kawakatsu and S. Matsushita, Lipids, 16, 427 (1981).

27) K. Kanazawa, G. Danno and M. Natake, Agric. Biol. Chem., 39, 1177 (1975).

28) T. Asakawa and S. Matsushita, Lipids, 15, 137 (1980).

29) S. Minamoto, K. Kanazawa, H. Ashida, G. Danno and M. Natake, Agric. Biol. Chem., 49, 2747 (1985).

30) K. Kanazawa, S. Minamoto, H. Ashida, K. Yamada, G. Danno and M. Natake, Agric. Biol. Chem., 49, 2799 (1985).

31) G. M. Siu and H. H. Draper, Lipids, 17, 349 (1982).

32) R. P. Bird and H. H. Draper, Lipids, 17, 519 (1982).

33) G. M. Siu, H. H. Draper and V. E. O. Valli; J. Toxicol. Environ. Health, 11, 105 (1983).

34) E. N. Frankel, W. E. Neff, E. Selke and D. Weisleder, Lipids, 17, 11 (1982).

35) J. Terao, T. Ogawa and S. Matsushita, Agric. Biol. Chem., 39, 397 (1975). 